\title{
Development of Virtual Laboratory Experiments in iLabs
}

\author{
http://dx.doi.org/10.3991/ijoe.v9i6.3176 \\ A.V. Ostroukh, A.B. Nikolaev \\ Moscow Automobile and Road construction State Technical University (MADI), Moscow, Russia
}

\begin{abstract}
The article describes the experience of developing Internet-oriented cross-platform interactive visualization system objects and processes with the organization of computer access to real laboratory equipment, interfacing with packages research software and specialized scientific databases on engineering Automobile and Road Complex in teaching Moscow Automobile and Road construction State Technical University (MADI).
\end{abstract}

Index Terms-Virtual labs, e-learning resources, distance education technologies, e-learning, automated control systems, controller, computer network.

\section{INTRODUCTION}

The trend of development of virtual laboratory complexes suggests the appearance of software that could be adjusted to suit the requirements of different subject areas. The main concept of such a laboratory is that one object with a set of equipment is at the disposal of all workplaces. The server measures and monitors the object's reaction and receives and processes tasks received from the clients-laboratory workplaces. Each workplace has only a computer with software installed to control the object and server's laboratory equipment as well as to process, visualize and record experimental data. One of the modules of such a laboratory provides communication between equipment connected to the server side and a remote workplace via the Internet. It is required from the client side to have only a browser and a number of preinstalled specialized libraries.

As applied to technical education, the concept of a virtual educational laboratory is potentially focused on the realization of the above requirements for the computerization of engineering training, complies with ideas of open and remote education, and allows, at least partially, smoothing out the acuity of the currently existing problems of material support of educational process [1 - 8].

\section{WEB-LABORATORIES WITH REMOTE ACCESS}

\section{A. Figures and Tables}

When working with an educational system, providing a developed practical component (for example, a considered real experiment) with the active use of a personal computer, it is appropriate to use the concept of a virtual laboratory, or a shared laboratory in case it will be used by several students simultaneously.

Of particular interest are web-laboratories with remote access. These are realized by modification of the software of a lab with one laboratory server. In this case, students gain access to the equipment from any personal computer connected to the Internet. To start working, it is usually necessary to register at the laboratory's website, to download the methodological support, and to download the client application.

The structure of a web-laboratory with remote access is shown on Figure $1[1,6]$.

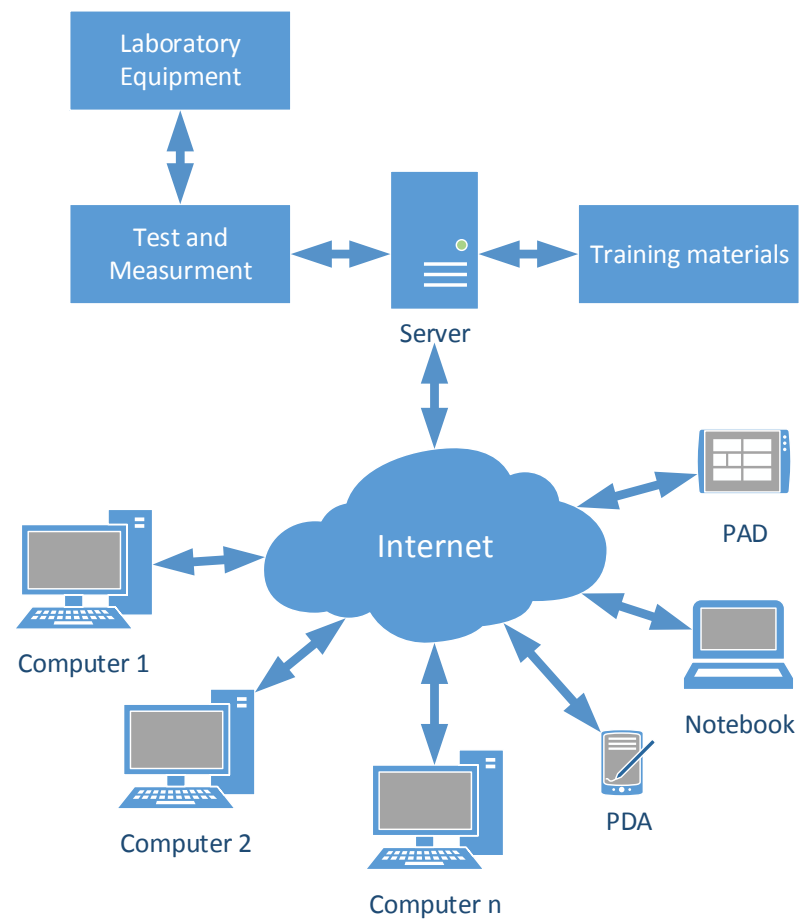

Figure 1. Web-laboratory with remote access structure

With such approach it is possible to get fundamentally new benefits: $[2,3,5,6]$

- $\quad$ one server of a virtual laboratory working on a 24hour basis serves a large number of study groups of a faculty member of one university or even several universities, including those in different cities;

- $\quad$ it is possible to eliminate duplication in preparation of training materials by different departments, faculties, and universities;

- unique conditions for enhancing of students' independent work with expensive equipment are created, as tasks can be performed at any time and in any place;

- the form of the laboratory experiments can be changed, so each student spends as much time as necessary for him, depending on his level of knowledge and skills; 
- instructors are exempt from routine work and can concentrate on the creative interpretation of techniques and customization of tasks according to the students' skills and abilities.

\section{HARDWARE AND SOFTWARE TOOLS FOR CREATION OF VIRTUAL LAB EXPERIMENTS}

For the design of systems that use certain equipment, such solutions have restrictions. That is why the virtual tools technology proposed by National Instruments stands out in the category of development tools. The powerful environment of graphic programming of this technology allows implementation of the necessary models of objects of study and use of a wide range of hardware (of different vendors) and a set of tools that is ideal for creation of major laboratory systems for the study of various disciplines [2, 3, 5]. When using the NI LabVIEW programming environment, the software developer has the following advantages:

1. Flexibility of created applications during the construction of measurement systems, achieved depending on the requirements of the problem, the computer platform used, and the necessity of filling the system with additional means of analysis and data display.

2. High ergonomics of created virtual devices from the point of view of the developed human-machine interface of measurement systems.

3. Wide range of tools, comprising:

- development of the user interface, working with the measuring and control equipment;

- processing of experiment results;

- development of network applications;

- processing of SQL-queries and support of remote databases;

- creation of a Common Gateway Interface (CGI), the use of web-server, and much more.

4. Opportunity for inclusion of developed applications into program modules written in other languages (Pascal, C, $\mathrm{C}++$ ).

Software products by National Instruments (LabVIEW, LabWindows, LabWindows / CVI, etc.) - are certified tools for software development for universal systems for general use. The company's equipment fully complies with international standards for measuring controlling devices and systems $[5,6,8]$.

The use of virtual tools technology makes it possible to create a unified set of program modules for shared laboratories, which gives an opportunity of flexible adjustment at each workplace. Hardware and software cores from National Instruments, used as the basis of the measuring component of the lab, make it universal in terms of the physical connection of objects of study of various subject areas.

\section{MADI CAMPUS Network With ILABS SERVER}

As a member of the Global Online Laboratory Consortium (GOLC) Moscow Automobile and Road Construction State Technical University (MADI) has access to the worldwide repository of virtual laboratory experiments-Lab2go (Figure 2).

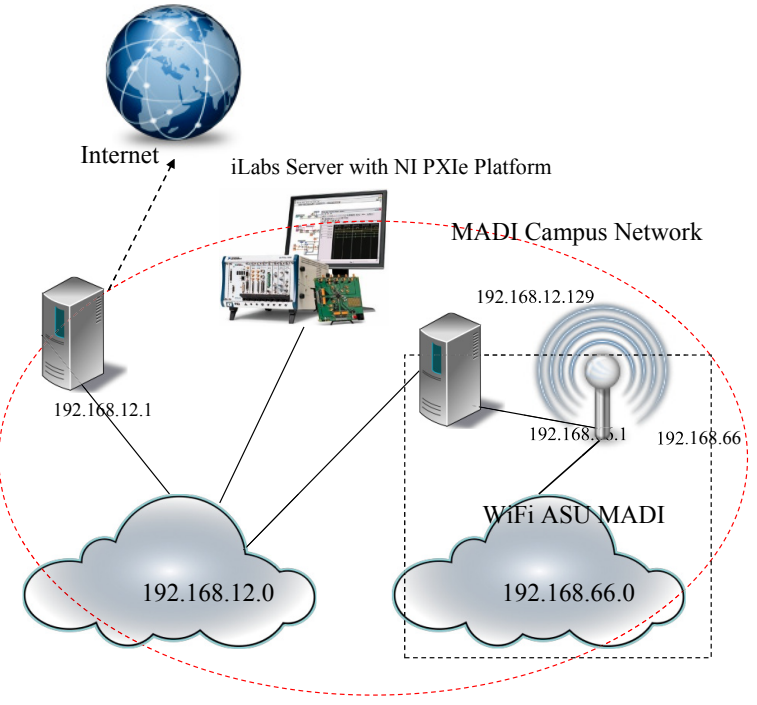

Figure 2. Pilot project iLabs in MADI

Created virtual laboratory experiments must have access to real laboratory equipment, have an opportunity to combine with research software packages and specialized databases for engineering disciplines in the auto-road complex (for use in the educational process in MADI), and be represented in the global repository of virtual laboratory experiments Lab2go.

The local area network of the Department "Automated Control Systems" MADI (ASU MADI) consists of two segments. 192.168.12.0 - a wired network. In this network are located classroom computers, a router connecting the LAN network of the department and institution, domain controllers, and file server as well as a wireless router with an IP-address 192.168.12.129. In a wireless network, the 192.168.66.0 router has this IP-address 192.168.66.1. The IP-address of the access point is 192.168.66.2. Laboratory installation on a platform that is running PXIe iLabs is connected to a wired network, so access is provided there as well as from the local network and the Internet.

\section{CONCLUSION}

Practical and laboratory classes play an important role in the modern educational process. Often the percentage of the acquired material depends not only on the quality of the educational material but also on how to conduct the classes. An interactive way of learning allows organizations to visualize the extent and nature of the influence of various physical parameters and initial and boundary conditions in the study of mathematical models $[6,8]$. The practice of the system of virtual laboratories has a significant impact on the learning process of students and leads to higher quality learning.

\section{REFERENCES}

[1] A.V. Ostroukh, K.A. Barinov, A.V. Bugaev , D.A. Burov Experience in the development and use of role-playing games for the training and retraining of industrial and transportation complex // Scientific Bulletin MSTUCA . - 2009 . - No. 141. - pp. 188-197

[2] A.V. Ostroukh, M.N. Krasnyanskiy , S.V. Karpushkin , D.L. Dedov. The integration of virtual simulators in the process of training of operators of technical systems using Internet technology // Distance and virtual learning . - 2010 . - No. 7. - pp. 66-70 .

[3] A.V. Ostroukh, S.A. Vasyugova, M.N. Krasnyanskiy, A. Samaratunga. The research prospects and challenges of integrating 
PAPER

DEVELOPMENT OF VIRTUAL LABORATORY EXPERIMENTS IN ILABS

human-computer : artificial intelligence, robotics, technological singularity and virtual reality // Prospects of science. - 2011 . No. 4 (19). - pp. 109 - 112

[4] A.V. Ostroukh, J.G. Podkosova, O.O. Varlamov, M.N Krasnyanskiy. An analysis of the prospects of using virtual reality technology in distance learning // Problems of modern science and practice. University. V.I. Vernadsky. - 2011 . - No. 2 ( 33). - pp. $104-111$

[5] A.V. Ostroukh, M.N. Krasnyanskiy, K.A Barinov, D.L Dedov, A.A. Rudnev. Virtual simulator systems for education and training of personnel of chemical and engineering industries // Vestnik TGTU . - 2011 . - V.17 . - No. 2 . - pp.497 - 501.

[6] A.V. Ostroukh . Experience in developing e-learning resources for a new generation of distance learning technology // In the world of scientific discovery . - 2011 . - No. 9 (21). - pp.149 -158

[7] A.V Ostroukh, A.U Malamute, K.A Barinov, M.N Krasnyanskiy, G.G Yagudaev. Algorithm for designing the virtual training complex for retraining Petrochemical Company // In the world of scientific discovery. Series "The problems of science and education." - 2012 . - No. 2.6 (26). - pp.168 -174
[8] A.V. Ostroukh, A.M. Merkulov, P.A. Petrikov, Y.P Bakatin. The principle of the development of training materials for the automated training petrochemical plants // In the world of scientific discovery. Series "The problems of science and education." - 2012 . - No. 2.6 (26). - pp.184 -193

\section{AUTHORS}

A.V. Ostroukh, Dr. of Science, professor, Department "Automated Control Systems", Moscow Automobile and Road construction State Technical University (MADI), Moscow, Russia (e-mail: ostroukh@mail.ru).

A.B. Nikolaev, Dr. of Science, professor, Department "Automated Control Systems", Moscow Automobile and Road construction State Technical University (MADI), Moscow, Russia (e-mail: nikolaev.madi@mail.ru).

Submitted 12 September 2013. Published as re-submitted by the authors22 October 2013. 